\title{
Elastic Linear Analysis of Connecting Rods for Single Cylinder Four Stroke Petrol Engines Using Finite Element Method
}

\author{
Didin Zakariya Lubis, Andoko* \\ Mechanical Engineering Department, Engineering Faculty, Universitas Negeri Malang, Jl. Semarang 5, \\ Malang, East Java, Indonesia \\ *Corresponding author: andoko.ft@um.ac.id
}

\begin{abstract}
A connecting rod is one of the most critical parts in engine assembly which transfers energy from the piston to the crankshaft. The connecting rod mainly undergoes tensile and compressive loading under engine cyclic process. The forces acting on the connecting rod are forces due to maximum combustion pressure and forces due to the inertia of the connecting rod. This research aimed to analyze the design of the connecting rod of single-cylinder four-stroke engines. This study used CAD software for modeling and structural design. Stresses generated across all the locations of the connecting rod were evaluated using FEA Software. Elastic linear analysis of model design was also performed. The simulation results in this study have led to the conclusion that failure occurred due to the incorrect selection of materials. Among all materials under study, AA 6061 is considered the most suitable material for use at high RPM. In fact, aluminum is preferable for use at high RPM.
\end{abstract}

Copyright $\odot$ 2019. Journal of Mechanical Engineering Science and Technology

All rights reserved

Keywords: Connecting rod, elastic linear, finite element analysis, internal combustion engine

\section{Introduction}

According to data released by the Central Statistics Agency (BPS) of Indonesia 2017, the number of motorcycles grew from 13,563,017 in 2000 to 92,976,240 in 2014, a six-fold increase. This number also shows that motorcycles are the most widely used motor vehicle in Indonesia. The increasing number of motorcycles in Indonesia leads to a vast number of accidents, particularly due to the failure of the engine components. One of the most frequent failures occurs in the connecting rod because of the static and dynamic forces that work there and heavy loads it withstands [1]. The topography of Indonesia, which consists of hills, lowlands and highlands and the poor quality of roads may also contribute to connecting rod failure. In addition, the failure of the connecting rod may also result from other factors, such as poor fabrication and lubrication processes [2]. Connecting rod is part of an internal combustion engine that forms a link between the piston and the crankshaft [3], [4]. There are several types of materials and various production processes to create connecting rods. The two most common materials are steel and aluminum, while the manufacturing process generally used is casting [5].

Casting is the preferable method of the production of connecting rods for motor vehicles. This method involves a series of process, including pouring molten steel into a mould and machining the finished product. The cast connecting rod can be used for lower horsepower-producing engines and is economical to manufacture. 
Connecting rods must be lightweight and have high stiffness. To achieve such properties, a lot of research has been conducted on various aspects of connecting rods such as materials, production technology, performance simulation, and fatigue. This study aimed to investigate the difference in stiffness between steel and aluminum alloy by using finite element modeling and comparison technique on the motorcycle engine of Honda Supra X 125.

\section{Materials and Methods}

\section{A. Materials}

In this research, a static stress analysis was conducted on connecting rods made of commonly used materials, i.e., AISI 4340 (Honda standard) and 1045 steel and proposed materials, i.e., AA 6061 and 7075. The chemical composition of the materials used is presented in Table 1.

Table 1. Chemical composition of connecting rods (\%wt) [9]

\begin{tabular}{cllll}
\hline & $\begin{array}{c}\text { Honda Original Part } \\
\text { AISI 4340 }\end{array}$ & \multicolumn{1}{c}{ Common uses } & \multicolumn{2}{c}{ Aluminum Alloy } \\
& \multicolumn{1}{c}{ AISI 1045 } & \multicolumn{2}{c}{ AA 6061 } & \multicolumn{1}{c}{ AA 7075 } \\
\hline $\mathrm{Al}$ & - & - & $95.80-98.60$ & $87.10-91.40$ \\
$\mathrm{Fe}$ & $95.19-96.33$ & $98.51-98.98$ & 0.70 & 0.50 \\
$\mathrm{Cu}$ & - & - & $0.15-0.40$ & $1.20-2.00$ \\
$\mathrm{Mg}$ & - & - & $0.80-1.20$ & $2.10-2.90$ \\
$\mathrm{Cr}$ & - & - & $0.04-0.35$ & $0.18-0.28$ \\
$\mathrm{Zn}$ & - & - & 0.25 & $5.10-6.10$ \\
$\mathrm{Si}$ & $0.15-0.30$ & $0.10-0.35$ & 0.60 & 0.40 \\
$\mathrm{C}$ & $0.37-0.43$ & $0.43-0.50$ & - & - \\
$\mathrm{Mn}$ & $0.60-0.80$ & $0.60-0.90$ & 0.15 & - \\
$\mathrm{P}$ & 0.03 & 0.04 & - & - \\
$\mathrm{S}$ & 0.04 & 0.05 & - & - \\
\hline
\end{tabular}

\section{B. Numerical Evaluation of Maximum Loading Condition of Connecting Rod}

It is assumed that the forces acting on the connecting rod are forces on the piston due to combustion pressure and tensile forces due to inertia and pressure of the bearing. The mechanical properties of the materials are shown in Table 2 [6].

Table 2. Mechanical properties of different materials used for connecting rods [9]

\begin{tabular}{lllll}
\hline & AISI 4340 & AISI 1045 & AA 6061 & AA 7075 \\
\hline Young's modulus & $190 \times 10^{9} \mathrm{~Pa}$ & $200 \times 10^{9} \mathrm{~Pa}$ & $68.9 \times 10^{9} \mathrm{~Pa}$ & $71.7 \times 10^{9} \mathrm{~Pa}$ \\
Poisson's ratio & 0.27 & 0.29 & 0.33 & 0.33 \\
Density of material & $7850 \mathrm{Kg} / \mathrm{m}^{3}$ & $7870 \mathrm{Kg} / \mathrm{m}^{3}$ & $2700 \mathrm{Kg} / \mathrm{m}^{3}$ & $2810 \mathrm{Kg} / \mathrm{m}^{3}$ \\
Ultimate Tensile Strength & $745 \times 10^{6} \mathrm{~Pa}$ & $565 \times 10^{6} \mathrm{~Pa}$ & $290 \times 10^{6} \mathrm{~Pa}$ & $572 \times 10^{6} \mathrm{~Pa}$ \\
Yield strength & $470 \times 10^{6} \mathrm{~Pa}$ & $310 \times 10^{6} \mathrm{~Pa}$ & $276 \times 10^{6} \mathrm{~Pa}$ & $503 \times 10^{6} \mathrm{~Pa}$ \\
\hline
\end{tabular}


Table 3 shows the overall engine specification based on the data from Honda [8].

Table 3. Design specifications of connecting rod

\begin{tabular}{lll}
\hline No. & Properties & Nominal \\
\hline 1. & Torque $(\boldsymbol{\tau})$ & $9.58 \mathrm{Nm} / 6308 \mathrm{rpm}$ \\
2. & Connecting rod length $(\boldsymbol{l})$ & $0.1 \mathrm{~m}$ \\
3. & Cylinder Diameter $(\boldsymbol{d})$ & $52.4 \times 10^{-3} \mathrm{~m}$ \\
4. & Stroke $(\boldsymbol{s})$ & $57.9 \times 10^{-3} \mathrm{~m}$ \\
5. & Stroke volume & $124,89 \mathrm{cc}$ \\
6. & Compression ratio & $9.3: 1$ \\
\hline
\end{tabular}

a) Forces due to gas pressure

The volume of the combustion chamber was measured by the compression ratio. Where:

Density of petrol at $15^{\circ} \mathrm{C}\left(288.85^{\circ} \mathrm{K}\right)(\rho) \quad=770 \times 10^{-3} \mathrm{~kg} / \mathrm{m}^{3}$

Molecular weight $(\mathrm{M}) \quad=114.228 \mathrm{~g} / \mathrm{mol}$

Ideal gas constant $(\mathrm{R}) \quad=8.3143 \mathrm{~J} / \mathrm{mol} \cdot \mathrm{k}$

Calculating the mass:

$\mathrm{m}=\rho \cdot \mathrm{v}$

$\mathrm{m}=770 \times 10^{-3} \cdot\left[3.14\left(\frac{52.4 \times 10^{-3}}{2}\right) 2.57 .9 \times 10^{-3}\right]$

$\mathrm{m}=0.007335 \mathrm{~kg}$

Defining the $\mathrm{R}_{\text {specific: }}$

$R_{\text {specific }}=\frac{R}{M}$

$R_{\text {specific }}=\frac{8.3143}{0.114228}=72.78 \mathrm{~J} / \mathrm{kg} \cdot \mathrm{K}$

Ideal gas equation,

$\mathrm{P}=\frac{m \cdot R_{\text {specific }} \cdot T}{V}$

$\mathrm{P}=\frac{0.007335 \cdot 72.78 \cdot 288.85}{9526.6^{-6}}$

$\mathrm{P}=16186.3 \mathrm{~Pa}$

b) Inertia force due to reciprocating mass

Mass of the AISI 4340 material:

$\mathrm{m}=$ mass of (piston rings and piston pin $+\frac{1}{3}$ rd of connecting rod)

$\mathrm{m}=0.5+\left(\frac{1}{3} \cdot 0.9\right)$

$\mathrm{m}=0.8 \mathrm{~N}$

$\omega=\frac{2 \cdot \pi \cdot n}{60}$

$\omega=\frac{2 \cdot 3 \cdot 14 \cdot 6308}{60}=660.2 \mathrm{rad} / \mathrm{s}$

$\mathrm{r}=\frac{\text { Stroke of piston }}{2}$ 
$\mathrm{r}=\frac{57.9 \times 10^{-3}}{2}=28.95 \times 10^{-3} \mathrm{~m}$

$\theta=0$ (considering that connecting rod is at the TDC position)

Inertia force of AISI 4340 material:

$$
\begin{aligned}
F_{i} & =\mathrm{m} \omega^{2} \mathrm{r}\left(\cos \theta+\frac{\mathrm{r} \cos \theta}{\mathrm{l}}\right) \\
F_{i} & =0.8 .660 .2^{2} \cdot 28.95 \times 10^{-3}\left(1+\frac{28.95 \times 10^{-3} \cdot 1}{0.1}\right) \\
F_{i} & =13018.6 \mathrm{~N}
\end{aligned}
$$

The results of a calculation using the same equation showed the inertia forces of AISI 1045, AA 6061, and AA 7075.

Table 4. Inertia force of each material under study

\begin{tabular}{lll}
\hline Material & Mass $(\mathbf{N})$ & Inertia force $(\mathbf{N})$ \\
\hline AISI 1045 & 0.83 & 13506.6 \\
AA 6061 & 0.61 & 9926.7 \\
AA 7075 & 0.62 & 10089.4 \\
\hline
\end{tabular}

\section{Modeling of Connecting Rod}

The connecting rod was designed following the dimensions of the regular connecting rods used in motorcycle engines from Honda. The specification of the connecting rod by solid modeling is presented in Fig 1. A finite element analysis under the influence of compressive and tensile stress due to combustion and inertia was performed using FEA Software. A linear elastic stress analysis was also conducted on the connecting rod model. The connecting rod should not experience buckling and fatigue under the working loads. Fig 2 shows the loading conditions for the connecting rod.

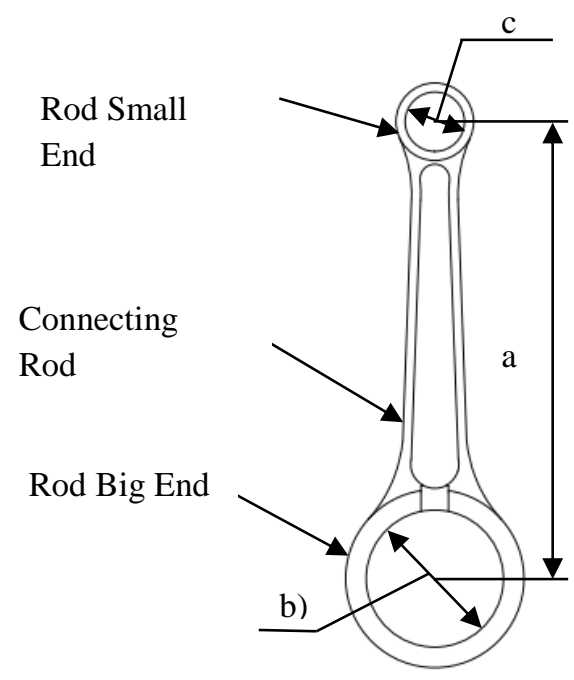

Fig 1. Connecting rod model; a) $100 \mathrm{~mm}$; b) $30 \mathrm{~mm}$; c) $13 \mathrm{~mm}$ 


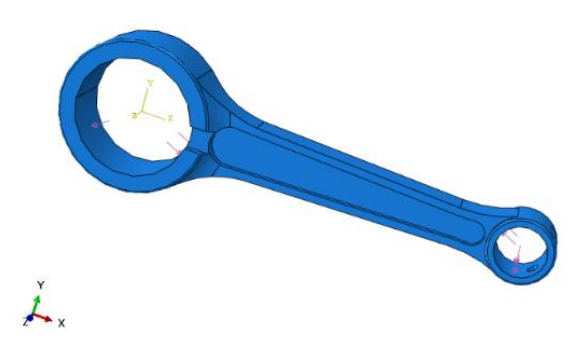

Fig 2. Loading conditions for connecting rod

\section{Result and Discussion}

\section{A. Mesh sensitivity study}

A mesh sensitivity study or convergence test is an analysis to determine the number of elements by showing appropriate values acceptable in a finite element analysis [7]. The mesh sensitivity study showed an insignificant difference in von Mises values. The element mesh used in this study was the adjustment of the number of elements in the model, starting from a small number of elements (very coarse) to a large number of elements (very fine).

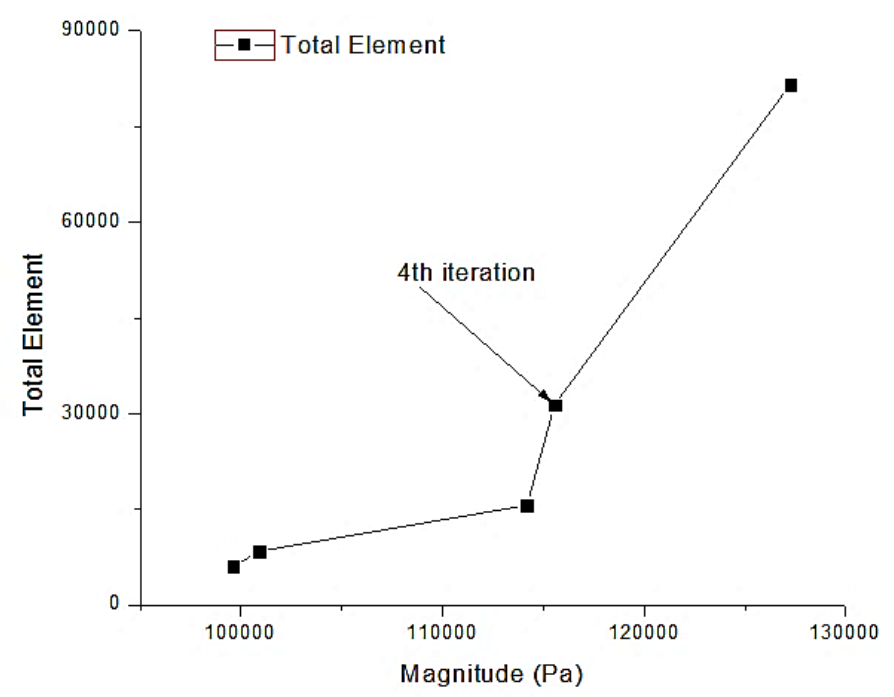

Fig 3. Mesh sensitivity study of connecting rod for AISI 4340

Fig 3 suggests that the more the number of elements, the greater the value of von Mises stress. The maximum von Mises stress on the AISI 4340 connecting rod as a convergent sample was at the fourth iteration with several elements 31406 . Furthermore, this number of elements then used in the modeling of the connecting rods.

\section{B. Results of the elastic linear analysis on connecting rod}

The results of the finite element analysis using FEA Software are presented in Table 5. The materials used were in safe condition based on the maximum working stress for 
each material. The AISI 4340 material had maximum stress of $118.7 \mathrm{MPa}$, less than the allowable yield strength of the material, i.e. $310 \mathrm{MPa}$ (see Fig 4).
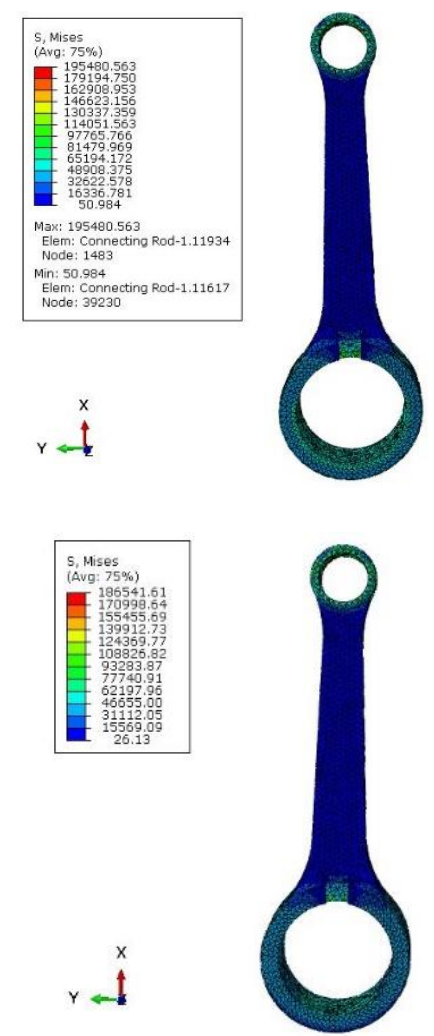
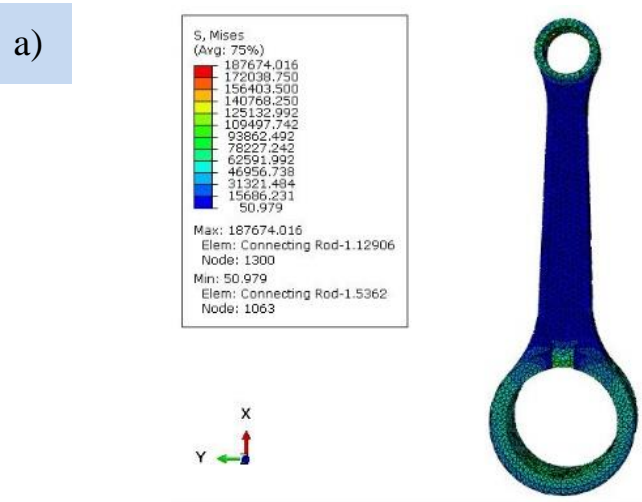

c)

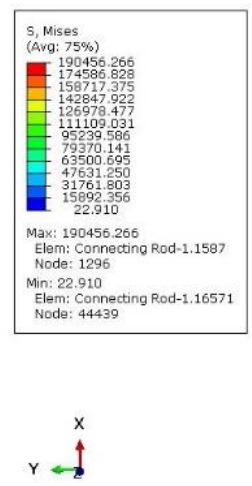

b)

Fig 4. The elastic stress comparison results of finite element analysis on the materials a) AISI 4340; b) AISI 1045; c) AA 6061; d) AA 7075

The design of the connecting rod model was considered safe, if only under static loading conditions. The lowest stress of $186.5 \mathrm{MPa}$ occurred in the proposed material (AA 6061) with an allowable yield strength of $276 \mathrm{MPa}$. This result suggested a material with a lighter material mass. When subjected to an inertia load, the mass was one of the multiplier factors comparable to the inertia force. Fig 5 shows the comparison of the maximum stress in the connecting rod model.

Table 5. Characteristics of connecting rods simulated using element analysis with tetrahedral shaped elements

\begin{tabular}{lcc}
\hline Connecting rod Material & No. of element & Von Mises stress (MPa) \\
\hline AISI 4340 & 31406 & 195.4 \\
AISI 1045 & 31303 & 187.6 \\
AA 6061 & 31303 & 186.5 \\
AA 7075 & 30815 & 190.4 \\
\hline
\end{tabular}




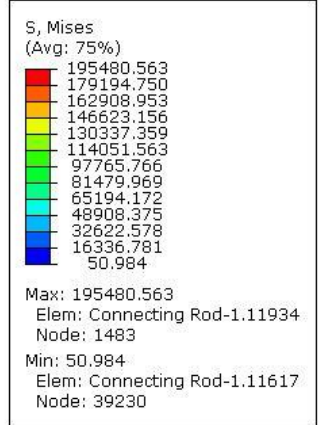

a)

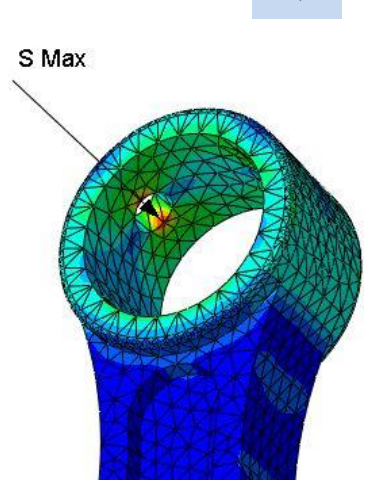

c)

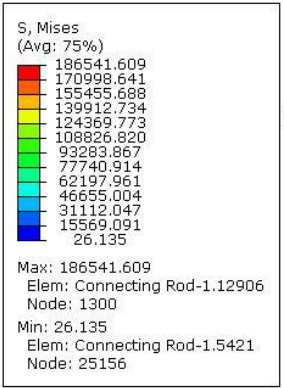

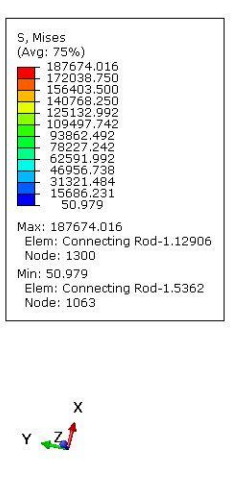

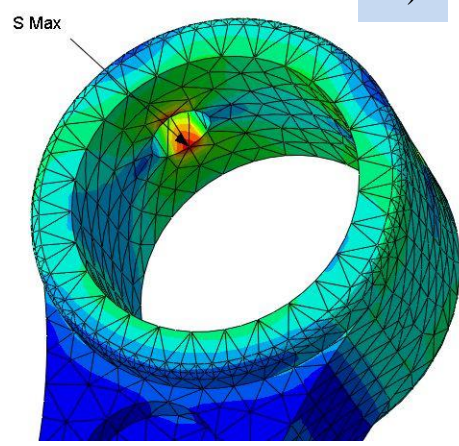

d)

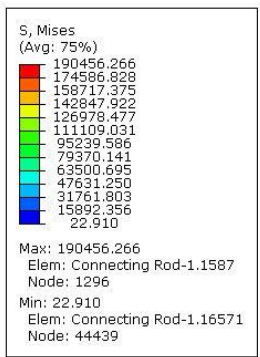

b)

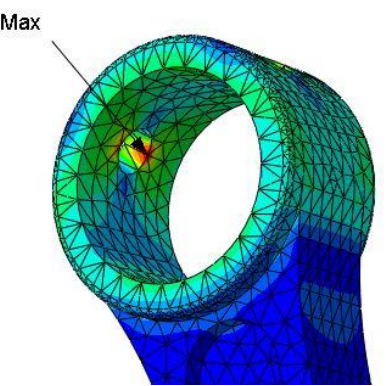

$s$ Max

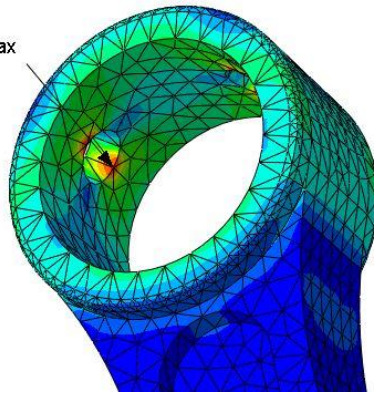

Fig 5. Von mises stress maximum comparison on the material study a) AISI 4340; b) AISI 1045 ; c) AA 6061; d) AA 7075

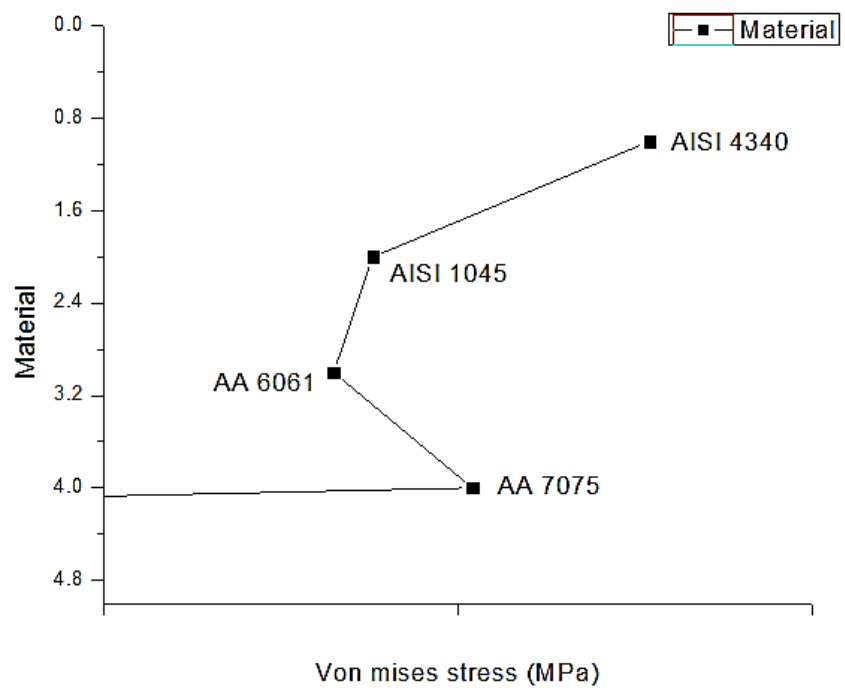

Fig 6. Von Mises stress of each material

As put forward by [1], the greatest stress occurs at the small end of the connecting rod. Therefore, connecting rod failure is more likely to happen at the oil hole and the fillet section of the big end of connecting rod. Also, even though the maximum stress is 
less than the allowable material stress, fatigue failure can occur under dynamic loads due to high-stress concentrations and material defects. Some of the major factors determining the damage to the connecting rod include connecting rod hardness, connecting rod design, clearance between the bearing and crank pink that exceeds its limit, and poor engine lubrication. Fig. 6 shows the maximum stress of each material.

\section{Conclusion}

The simulation results in this study have led to the conclusion that failure occurred due to the incorrect selection of materials. Among all materials under study, AA 6061 is considered the most suitable material for use at high RPM. In fact, aluminum is preferable for use at high RPM.

Aluminum is a material of choice for connecting rods due to its lightweight. Besides good throttle response, its lighter weight can minimize vibration and stress on the connecting rod. However, steel is recommended for use in high-performance engines because aluminum will stretch more than steel under the same load.

\section{Nomenclature}

$\begin{array}{ll}F & \text { engine force }(\mathrm{N}) \\ v & \text { volume }\left(\mathrm{m}^{3}\right) \\ S & \text { engine stroke }(\mathrm{m}) \\ a & \text { cylinder area }\left(\mathrm{m}^{2}\right) \\ P & \text { pressure }(\mathrm{Pa}) \\ m & \text { mass }(\mathrm{N}) \\ \omega & \text { angular speed }(\mathrm{rad} / \mathrm{s}) \\ r & \text { crank radius }(\mathrm{m}) \\ \theta & \text { crank cycle } \\ l & \text { length of connecting rod } \\ F_{i} & \text { inertia force due to reciprocating mass }(\mathrm{N}) \\ \mathrm{T} & \text { temperature }\end{array}$

\section{References}

[1] D. Gopinath and C. V Sushma, "Design and Optimization of Four Wheeler Connecting Rod Using Finite Element Analysis," Mater. Today Proc., vol. 2, no. 4-5, pp. 2291-2299, 2015.

[2] C. Juarez, F. Rumiche, A. Rozas, J. Cuisano, and P. Lean, "Case Studies in Engineering Failure Analysis Failure analysis of a diesel generator connecting rod," Biochem. Pharmacol., vol. 7, pp. 24-31, 2016.

[3] S. Rakic, U. Bugaric, I. Radisavljevic, and Z. Bulatovic, "Failure analysis of a special vehicle engine connecting rod," Eng. Fail. Anal., vol. 79, no. August 2016, pp. 98-109, 2017. 
[4] M. N. Ilman and R. A. Barizy, "Failure analysis and fatigue performance evaluation of failed connecting rod of reciprocating air compressor," Eng. Fail. Anal., vol. 56, no. April, pp. 142-149, 2015.

[5] D. Visser, "A Comparison of Manufacturing Technologies in the Connecting Rod Industry," Department of Metallurgical and Materials Engineering, 2008.

[6] J. R. Davis, Aluminum and Aluminum Alloys. ASM International, 2001.

[7] D. V. Hutton, Fundamentals of Finite element analysis. McGraw-Hill Companies, 2004.

[8] AHM. (https://www.astra-honda.com/product/supra-x-125-fi). PT. Astra Honda Motor.

[9] ASM International, Volume 2: Properties and Selection: Nonferrous Alloys and Special-Purpose Materials (https://www.asminternational.org/). 1993. 